\title{
Fresh Snack Food Channel Evaluation Model for Integrating Customers' Perception of Transaction Costs in Taiwan
}

\author{
Po-Yu Chen \\ Department of Advertising and Strategic Marketing, Ming Chuan University, No. 250, Sec. 5, Zhong Shan N. Rd., Taipei 111, Taiwan \\ Correspondence should be addressed to Po-Yu Chen; chenboy@mail.mcu.edu.tw
}

Received 5 March 2017; Accepted 8 May 2017; Published 31 May 2017

Academic Editor: Latiful Bari

Copyright (C) 2017 Po-Yu Chen. This is an open access article distributed under the Creative Commons Attribution License, which permits unrestricted use, distribution, and reproduction in any medium, provided the original work is properly cited.

\begin{abstract}
The primary purpose of this study was to explore how food dealers develop methods that facilitate transaction efficiency and how they select the optimal food channels. This study establishes a model according to the impact of transaction cost factors on consumers' decision-making regarding purchase of fresh snack foods. Using fresh snack foods in Taiwan as an example, this study employed a fuzzy analytic network process to solve decision-making problems with multiple criteria by comparing the interaction between each transaction cost factor to obtain the factor weightings as well as the weightings of the transaction costs at each decision stage. This study found that food safety assurance and providing sufficient nutrition information were the most essential topics; thus, the optimal choice for snack food producers is to develop retail outlets. This study construction process proposed is innovative and operational, and the results may provide a reference for snack food dealers or microfood enterprises to assist them in developing their food channels.
\end{abstract}

\section{Introduction}

The rise of the Internet has enabled the rapid flow of information and various improvements in life convenience, both of which have led to various lifestyle changes. Compared with the short supply of snack foods in earlier times, snack foods have shifted from being luxury goods to being normal goods. Snack foods are known as "finger foods" in Japan and simply "snacks" in China. In fact, snack foods have existed for a long time, although the term was introduced only in recent decades. Conventional snack foods include peanuts, melon seeds, packaged dry noodles, Ramune soda, and preserved fruit, and more recently introduced snack foods include potato chips, chocolates, chewing gum, and instant noodles. Because of the increasing trend of Western cake with coffee food culture emerging in Taiwan in recent years, as well as the substantial reduction in tariffs following Taiwan's accession into the World Trade Organization in 2002, food and beverage industries have been constantly introducing snacks, desserts, and pies with distinct national characteristics. The quality of the snack food market has been markedly affected by rapid changes in the types of snack foods that are available, their sale through convenience store sales channels (Taiwan has the highest density of convenience stores in the world), and the introduction of the home delivery distribution model.

The qualitative effect on the snack food market is that the industries can sell their products through online platforms, which lowers the market entry threshold for leisure goods. For example, established traditional market snack industries that own stores can also expand into online channels. Following the rise of health awareness, customers have placed greater emphasis on food freshness. Home deliveries using preservation technologies such as low-temperature storage and freezers have overcome food freshness and regional restrictions, allowing snack foods to become more diverse and resulting in substantial changes in their sales patterns. Ready-to-eat or cooked snack foods can be home-delivered and eaten after simple processing or heating. Examples of famous Taiwanese snack foods include Chou's shrimp rolls from Tainan and Wanluan pork knuckle. Under the current trend of the microenterprise model, various homemade desserts and pastries can be delivered to customers with adequate freshness and sufficient time until expiry, with home delivery techniques making up for the capital and equipment deficiencies of microenterprise. 
The quantitative effect on the snack food market stems from the lower transaction costs perceived by customers, which results in an increase in market size. In addition, customer-oriented market policies and high customer awareness prompt businesses to view customer access to product information and customer convenience in buying and using products as the most essential topics in product marketing. When facing the aforementioned problems, industries usually adopt approaches that improve transaction efficiency, such as additional sales branches establishment, home delivery, promoting website exposure, and providing online transaction services; or they directly absorb customers' partial transaction costs to stimulate demand. Therefore, how industries determine their resource input levels in promoting transaction efficiency (reducing customers' transaction costs) and prompt consumer purchasing behaviors is a topic worth investigating.

\section{Literature Review}

2.1. Transaction Cost Theory. Engel et al. [1] noted that customer purchasing decisions involve activities pertaining to obtaining, consuming, and disposing products or services, and these activities include pre- and postpurchase decisions. Blackwell et al. [2] studied customers' various purchasing factors and listed a series of activities involving obtaining, consuming, and disposing of products and services, including the processes involved in pre- and postpurchase decisions. Peter and Olson [3] showed that customers' purchasing decisions are dynamic interactions among cognitive, behavioral, and environmental outcomes throughout the process of individual life exchange. Recent customer behavior studies have focused on customers' consumption experiences and the various dynamically interacting factors affecting transactions throughout customer exchange processes. According to Williamson [4], Ronald Coase was the first to introduce the concept of transaction costs into industry and market analysis. Coase [5] posited that the price mechanism under the economic operation of specialization and exchange will have ex ante (such as information searching, contract negotiation, and signing costs) and ex post costs (costs for supervising contract execution), which are collectively known as transaction costs. Coase found that industries usually replace markets in fulfilling the function of economic coordination and can effectively save transaction costs. According to Teo and $\mathrm{Yu}$ [6], transaction cost theory became prominent only after Williamson [7] expanded Coase's original framework and published other relevant studies on trading and transaction costs. In measuring transaction costs, Liang and Huang [8] defined them as the cost of processes involving transactionrelated activities and divided the decision-making aspect of customer purchasing behaviors into three stages: prepurchasing, purchasing, and postpurchasing processes. Accordingly, the present study was based on transaction cost theory, which stems from the decision-making process in customer behaviors.
2.2. Customer-Perceived Transaction Costs. The Internet has caused qualitative changes in the composite factors of transaction costs in recent years. For example, Degeratu et al. [9] found that information searching costs differ according to the attributes of products and that appropriate product exposure or better service can reduce customers' searching costs [10]. Earlier studies have shown that the immediacy of interactions on the Internet can lower negotiation costs during transactions. An example of this is the question and answers sections that some companies provide on their websites [11, 12], and online interaction has also been shown to promote consumer trust $[13,14]$. The development of credit card and third-party payment online transaction mechanisms and tools has facilitated reducing transaction costs and promoted purchasing behaviors [15]. Zhang and Oh [16] and Workman and Cho [17] have empirically investigated the impacts of product display, trial use, or food testing on consumers; however, they have also been shown to pose a security risk and thus challenge consumer trust in online transactions [6].

The diversity of products that customers currently face in the market raises the question of how they conduct their purchasing and selection behaviors when deciding between the various brands, prices, payment methods, dealers, and distributors that are available. Liang and Huang [8] stated that when choosing between products with similar attributes or prices, customers will choose those that have lower transaction costs or purchase from suppliers that provide the highest value $[6,18-22]$. Empirical studies have discussed the differences in transaction costs between online and offline shopping contexts, as well as the relationship between online shopping information and transaction costs [10, 23, 24]. Tyagi [25] verified that an increase in dealers' investments in transaction costs reduces customers' transaction costs. However, previous studies investigating the problem of waiting time cost differences in the goods obtained by different customers (meaning a different time cost for each customer) have been limited to superficial discussions of the concept. In fact, customers may adopt different purchasing decisions based on the length of waiting time, because this directly affects the remaining effective period (expiry date) of the products (or food), which is particularly pertinent for products whose quality is defined by the level of freshness. The effects of waiting time costs and product (or food) freshness on customer demand have been widely studied in the field of inventory, and various relevant models have been developed [26, 27]. However, previous customer studies and food research have rarely mentioned the perceived waiting time and food freshness costs; this might be due to the lack of operability for measuring the time cost, which varies from person to person.

2.3. Channel Decisions. With the current prevalence of Internet marketing, businesses understandably invest considerable resources into developing Internet marketing strategies. Previous studies have indicated that most dealers adopt multiple channels for product sales, whereby the level of investment for developing new customers is also lower [28, 29]. Many consumers have become multichannel users under such an environment, although enterprises may also lose customers during the shopping process, particularly those who 
tend to research products online before purchasing them in a brick-and-mortar store [11]. When marketing through multiple channels, enterprises must also account for the wide variability in the composition of customers' transaction costs [30, 31]. Despite developing multiple channels being the optimal marketing strategy for enterprises, they encounter problems in balancing the amount of investment or resource allocation in different channel types [32,33].

Suppliers' channel development simultaneously affects their production strategies and inventory costs. For example, a supplier sells its products through multiple channels, but customers' transaction decisions in choosing retail outlets or Internet purchasing may differ when transaction costs are considered [11]. Suppliers adopt the nonimmediate delivery (or even preorders) of products in response to customers' Internet orders, and this can enable them to be more responsive in adjusting their production lines, which effectively controls the level of inventory. Thus, channel decisions are particularly critical for fresh food suppliers, whereby effective channel strategies ensure that products retain adequate freshness when they reach the customers. Although previous food suppliers have used various methods to estimate product demand, the expiry dates of fresh foods mean that the increase in customers' transaction costs when food loses its freshness (or when the waiting time increases) should be considered. Therefore, the optimal means for facilitating transaction efficiency should be determined, because a lack of an operational model still leads to difficulties in production decisions [32, 34].

Current trends in the snack food market show that customers are fastidious with a greater emphasis on affordability, practicality, health, nutritional value, food hygiene, and freshness in their snack food purchases. In addition, the demand for functional, organic, and fiber-rich foods results in a richer snack food market with new food types emerging. From the perspective of Taiwan, the snack food market is the most dynamic segment of the food industry with a wide customer age range and diverse product types. In particular, there are various distributors providing access to snack foods, and their channel types can be roughly divided into discount stores; general merchandise stores; snack food chain stores; convenience stores; traditional shops and grocery stores; markets, night markets, and street vendors; and others. The development and progress of online platforms has also resulted in the emergence of Internet ordering or home delivery services as well as multichannel platforms such as TV shopping.

2.4. Fuzzy Analytic Network Process. In the present study, a type of resource allocation decision model was developed to explore the interaction between transaction cost elements under different channel types. The multiple criteria decisionmaking (MCDM) methods are the most suitable methods for resolving decision problems under uncertainty with multiple evaluation criteria. MCDM provides a systematic approach that helps decision-makers combine the inputs with profit/cost information and stakeholder perspectives in order to rank all the alternatives to the item. The MCDM framework contains various methods, such as the weighted sum model (WSM), weighted product model (WPM), and the analytic hierarchy process (AHP), whereas the analytic network processes (ANP) are an extension of the AHP. The ANP can add a feedback mechanism to the hierarchical framework in the decision-making model, which can indicate the dependence between each hierarchical criterion.

Evaluators use clearly defined values for measurement in a conventional decision-making process, although it is difficult to use the same approach for evaluation and measurement in actual environments in the presence of uncertainty. The main reasons are that human thinking is subjective and ambiguous, and the various selected factors and criteria will possess similarity problems because of speech defects [35]. In other words, it is impossible to draw from the experts' complete, accurate, and reliable knowledge and simultaneously conduct alternative evaluations with respect to the various standards and similar criteria. Because of the fuzziness in decision-making, as mentioned, measuring it using a fuzzy set theory-based approach should be a feasible solution [36].

In terms of revising the aforementioned MCDM method, the fuzzy analytic network process (FANP) is one the most suitable methods for resolving decision problems under uncertainty with multiple evaluation criteria. FANP integrates ANP [37, 38] with fuzzy set theory [39]. The ANP method compiles expert opinions whereby the complex evaluation problems are systematized and stratified, after which they are subjected to pairwise comparisons by decisionmakers who determine the weights between multiple evaluations. The correlations between the criteria of each level are considered, whereby a prioritized arrangement of decisionmaking is established for all of the evaluation criteria. To incorporate the uncertain and fuzzy characteristics of the subjective factors of human thinking, reasoning, and perception toward environmental surroundings, the ANP linguistic variable value is incorporated into the triangular fuzzy number and becomes FANP, which still operates according to fuzzy set theory. FANP has the advantage of displaying the fuzzy phenomenon of expert cognition without eliminating any unique opinions. The fuzzy intervals of the experts' collective decision-making can be used as the flexible space for decision-makers in judgments based on their personal experience.

FANP has been widely used in various fields of research in recent years. For example, some scholars have used it to develop supplier selection models (e.g., [40-44]), whereas others applied it to transportation choice decision-making problems (e.g., [45]), selection models for developing new product concepts [46], sustainable energy technology alternatives [47], hotel management system problem selection [48], and oversight problems in food management and research [49] and to determine the key indicators of green supply chain for food products [50]. MCDM has been adopted to explore the development of new product by century-old enterprises [51], improve productivity in smallscale food enterprises [52], and study site selection problems in food distribution [53]. Baviera-Puig et al. [54] used a similar approach to analyze corporate social responsibility in the food industry and how companies successfully achieved 
social communication and meet the demands of the stakeholders. FANP has also been adopted to study design problems of food supply chains [55-57]. Despite the wide range of applications of FANP, information on the channel assessment problems in the literature is scarce. This may be due to the effects of different channels on customers' purchasing behaviors, which lack a specific operation model.

Based on this analysis, no specific mode of operation has been proposed for food distributors to consider the factors of consumer-perceived transaction costs and to determine the optimal level of investment for promoting transaction efficiency and developing multiple channels. To solve this type of problem, first, a method for measuring consumers' perceived transaction cost is required, particularly for measuring the time cost, which varies among individuals (e.g., food waiting times or food freshness). Chang and Chen [32] devised a demand function model incorporating the transaction costs of individual customer's purchasing decisions relative to the time costs, waiting time, and service time. They verified that the transaction costs of dealers and customers do not exhibit a zero-sum relationship. In other words, for every dollar that dealers absorb of the transaction costs, the overall transaction cost for customers is reduced by more than a dollar, which can reveal the optimal level of transaction costs for industries to absorb to facilitate transaction efficiency. Therefore, the present study adapted the transaction cost measurement method proposed by Chang and Chen [32] and simultaneously accounted for the waiting time cost, food freshness, and service level to bring research on the effects of transaction cost factors on customers' purchasing behavior of fresh snack food in line with actual circumstances. Next, FANP was combined to solve the multicriteria decision-making problem. The main purpose of this study was to explore how dealers develop methods that foster transaction efficiency and to investigate their process for selecting the optimal food channels from the perspective of the food dealers. The model construction process proposed in the present study is more innovative and operational than previous ones.

\section{Pattern Construction and FANP Analysis Procedures}

This study constructed a weighted model composed of transaction cost factors under different channels. The model construction and analysis steps are described as follows.

Step 1. The transaction cost dimensions and criteria in each customer decision-making dimension were constructed. Textual analysis was performed to develop the transaction cost factors in each decision-making dimension of customer purchasing behaviors, after which marketing departments and research scholars were requested to revise the content and construct the evaluation dimensions and criteria of transaction costs in each decision-making dimension; the definitions are shown in Table 1.

Step 2. Construct the ANP hierarchical structure.
Step 2.1. The ANP assumption methods are as follows by Saaty and Vargas [38]. (1) A system can be broken down into multiple classes or components, forming a network-like hierarchical structure. (2) The elements of each level in the hierarchy need not be independent. (3) The elements within each hierarchy level can be evaluated using some or all of the elements from the previous level. (4) An absolute numerical scale can be converted into a ratio scale during the evaluation of an element. (5) After pairwise comparisons have been performed, the hierarchical elements are processed in a positive reciprocal matrix. (6) The preference and intensity relations of the elements must satisfy the transitivity. (7) Considering the difficulty of complete transitivity, their degree of consistency is further tested. (8) The advantage degree of the elements can be calculated using the weighting principle.

Step 2.2. The relationship network diagram for the transaction costs of fresh snack food is constructed using the evaluation dimensions and criteria of Step 1, as shown in Figure 1.

Step 3. Construction of the fuzzy pairwise comparison matrix.

Step 3.1. The ratio scale is used as the scale for measuring the pairwise comparison matrix, whereby each evaluation factor is subjected to a pairwise comparison by using the evaluation scale to assess the relative importance of each assessment factor at the same level. This study reduced Saaty's 9-point scale to a 5-point scale, as suggested by Lai [58] (see Table 2 for definitions).

Step 3.2. Calculate the eigenvalues and eigenvectors of the comparison matrix. Assume there were $N$ criteria $\left(C_{1}, C_{2}\right.$, $\ldots, C_{n}$ ) and comparison matrix $A=a_{i j}$, wherein $a_{i j}$ represented the relative importance of criteria $C_{i}$ and $C_{j}$. For all $i$ and $j$, it is necessary that $a_{i i}=1$ and $a_{i j}=1 / a_{i j}$. Using the row vector averaging proposed by Saaty for nominalization, the calculation of the approximate weighting $W_{i}$ through (1) is as follows:

$$
W_{i}=\frac{\sum_{j=1}^{n}\left(a_{i j} / \sum_{i=1}^{n} a_{i j}\right)}{n}, \quad \forall i, j=1,2, \ldots, n .
$$

The pairwise comparison matrix $A$ fully satisfies $a_{i k}=$ $a_{i j} \cdot a_{j k}, \forall i, j, k$; thus, the approximate value of the maximal eigenvalue $\lambda_{\max }$ can be obtained from the following:

$$
A W=\lambda W \lambda_{\max }=\frac{1}{n} \sum_{i=1}^{n} \frac{(A W)_{i}}{W_{i}}
$$

Step 3.3. The consistency index (C.I.) is calculated using (3), whereby each pairwise comparison matrix is calculated to have C.I. $<0.1$, thus confirming their compliance to the criteria of judgment consistency.

$$
\text { C.I. }=\frac{\lambda_{\max }-n}{n-1} \text {. }
$$


TABLE 1: Evaluation dimensions and criteria.

\begin{tabular}{|c|c|c|c|}
\hline Dimension & & Criteria & Definition \\
\hline \multirow{3}{*}{ Prepurchasing (P1) } & Cla & Sufficient information exposure & $\begin{array}{l}\text { Level of detail and coverage of snack food information } \\
\text { content that reaches customers }\end{array}$ \\
\hline & $\mathrm{C} 1 \mathrm{~b}$ & Food testing & $\begin{array}{l}\text { Provide opportunities, methods, and occasions for } \\
\text { snack food testing }\end{array}$ \\
\hline & $\mathrm{Clc}$ & Food safety assurance provided & $\begin{array}{l}\text { Provide the ingredient sources, production verification, } \\
\text { and expiry date of snack foods }\end{array}$ \\
\hline \multirow{3}{*}{ Purchasing (P2) } & $\mathrm{C} 2 \mathrm{a}$ & Personal information leak prevention & $\begin{array}{l}\text { Minimize customer concerns regarding personal } \\
\text { privacy during purchases }\end{array}$ \\
\hline & $\mathrm{C} 2 \mathrm{~b}$ & Waiting time (e.g., checkout, queue) & $\begin{array}{l}\text { The time required to check customers' credentials or for } \\
\text { the queue to be cleared when customers checkout }\end{array}$ \\
\hline & $\mathrm{C} 2 \mathrm{c}$ & Multiple payment methods & $\begin{array}{l}\text { Provide multiple payment methods such as cash, credit } \\
\text { card, third-party payment, or cash on delivery }\end{array}$ \\
\hline \multirow{3}{*}{ Postpurchasing (P3) } & $\mathrm{C} 3 \mathrm{a}$ & Order tracking transparency & $\begin{array}{l}\text { Customers can instantly monitor product delivery } \\
\text { processes through the phone or Internet after ordering } \\
\text { snack foods }\end{array}$ \\
\hline & $\mathrm{C} 3 \mathrm{~b}$ & Delivery progress notification & $\begin{array}{l}\text { The manufacturers may, via message or E-mail, actively } \\
\text { communicate delivery information or expected time of } \\
\text { arrival of the product }\end{array}$ \\
\hline & $\mathrm{C} 3 \mathrm{c}$ & Waiting time for product delivery & $\begin{array}{l}\text { The waiting time before customers receive products } \\
\text { affects their satisfaction and repurchasing intentions }\end{array}$ \\
\hline
\end{tabular}

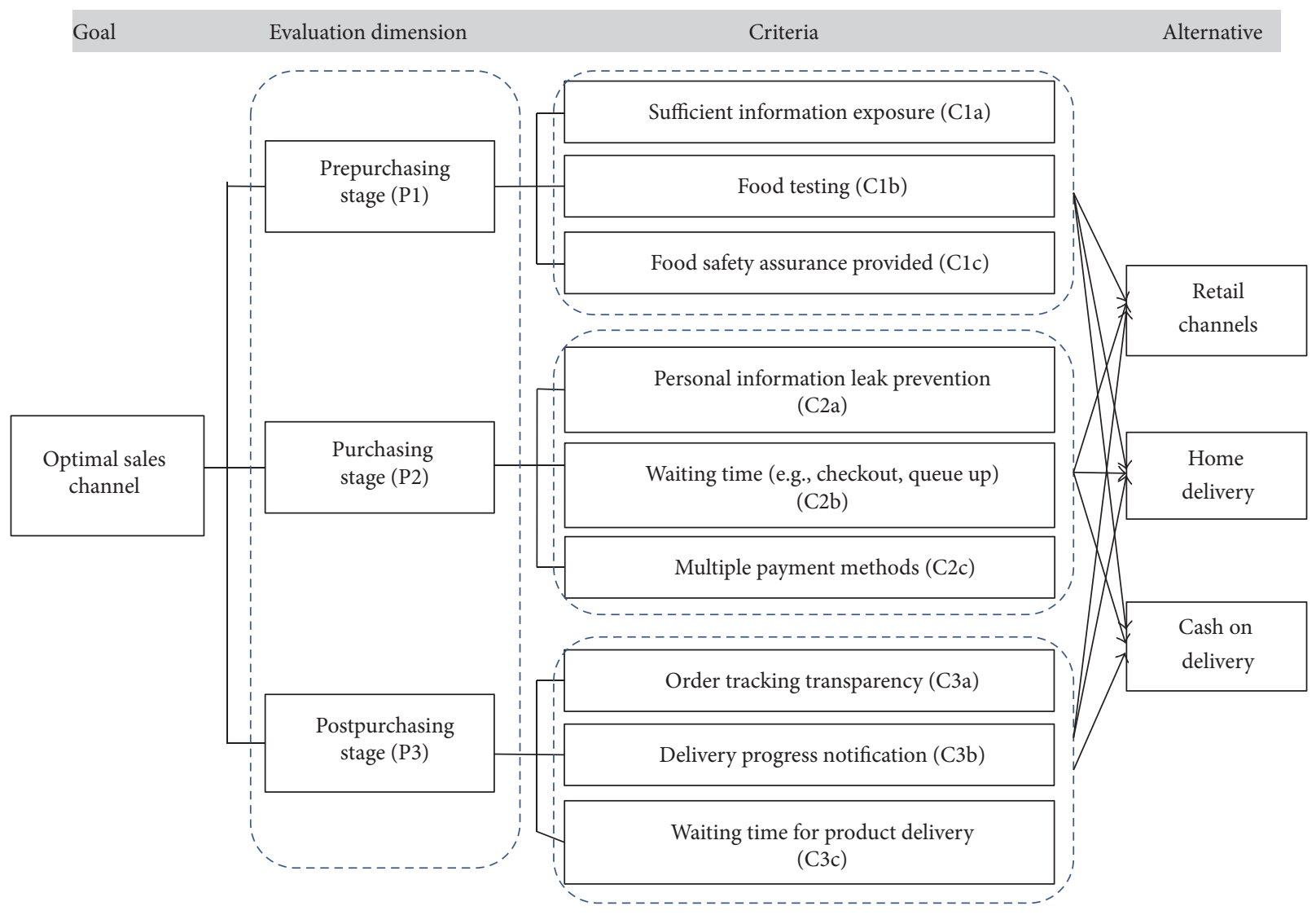

indicates that the elements within the clusters possess internal dependencies

FIGURE 1: Architecture diagram of fresh snack food marketing channels. 
TABLE 2: Definition of the ANP evaluation scale anchors.

\begin{tabular}{lll}
\hline $\begin{array}{l}\text { Evaluation } \\
\text { scale }\end{array}$ & Definition & Remarks \\
\hline 1 & $\begin{array}{l}\text { Equal } \\
\text { importance } \\
\text { Moderate } \\
\text { importance } \\
\text { Essential strong } \\
\text { importance } \\
\text { Very strong } \\
\text { importance }\end{array}$ & $\begin{array}{l}\text { The contributions of the two } \\
\text { compared plans are equally } \\
\text { important } \\
\text { Experience and judgment showing } \\
\text { a slight preference for a specific plan } \\
\text { strong preference for a specific plan } \\
\text { An extremely strong preference for } \\
\text { a specific plan } \\
\text { Sufficient evidence showing an } \\
\text { absolute preference for a specific } \\
\text { plan }\end{array}$ \\
\hline 5 & importance & \\
\hline
\end{tabular}

TABLE 3: Eigenfunction of triangular fuzzy numbers.

\begin{tabular}{lc}
\hline Fuzzy numbers & Eigenfunctions \\
\hline 1 & $(1,1,1)$ \\
2 & $(1,3,5)$ \\
3 & $(3,5,7)$ \\
4 & $(5,7,9)$ \\
5 & $(7,9,9)$ \\
\hline
\end{tabular}

Step 3.4. Convert the decision makers' and experts' linguistic variables into triangular fuzzy numbers " $\sim$ " to represent the subjective intensity. This improves the imbalances in the measuring scales of the ANP method to make the evaluation process smoother and define the eigenfunction of the symmetrical triangular fuzzy numbers $\sim($ see Table 3$)$.

Step 3.5. According to the range analysis method by Chang [59], the triangular membership function was used to represent the evaluation value between each criteria. Let $X=$ $\left\{x_{1}, x_{2}, \ldots, x_{n}\right\}$ denote the attribute level set and $U=$ $\left\{u_{1}, u_{2}, \ldots, u_{n}\right\}$ denote the target set. The range of values for each target set attribute level $g_{i}$ can be calculated and the range analysis value for $m$ is defined as follows:

$$
\widetilde{M}_{g_{i}}^{1}, \widetilde{M}_{g_{i}}^{2}, \ldots, \widetilde{M}_{g_{i}}^{n}, \quad i=1,2, \ldots, n,
$$

where $\widetilde{M}_{g_{i}}^{j}(j=1,2, \ldots, m)$ represents the triangular fuzzy number.

Step 3.6. The fuzzy comprehensive evaluation value according to the $i$ th target is calculated as follows:

$$
\widetilde{S}_{i}=\sum_{j=1}^{m} \widetilde{M}_{g_{i}}^{j} \otimes\left[\sum_{i=1}^{n} \sum_{j=1}^{m} \widetilde{M}_{g_{i}}^{j}\right]^{-1} .
$$

The fuzzy operation of $m$ range analysis values is conducted to obtain $\sum_{j=1}^{m} \widetilde{M}_{g_{i}}^{j}$ whereby a fuzzy analysis matrix is constructed:

$$
\sum_{j=1}^{m} \widetilde{M}_{g_{i}}^{j}=\left(\sum_{j=1}^{m} l_{j}, \sum_{j=1}^{m} m_{j}, \sum_{j=1}^{m} u_{j}\right) .
$$

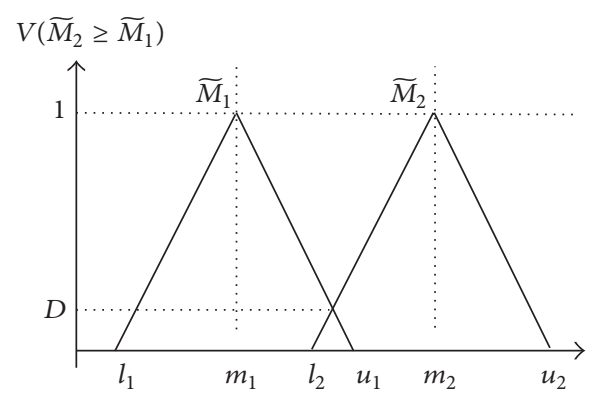

FigURE 2: Intersection graph of fuzzy numbers $\widetilde{M}_{1}$ and $\widetilde{M}_{2}$.

Through the fuzzy operation of $\widetilde{M}_{g_{i}}^{j}(j=1,=2, \ldots, m)$, the evaluation value of $\left[\sum_{i=1}^{n} \sum_{j=1}^{m} \widetilde{M}_{g_{i}}^{j}\right]^{-1}$ is obtained:

$$
\sum_{i=1}^{n} \sum_{j=1}^{m} \widetilde{M}_{g_{i}}^{j}=\left(\sum_{j=1}^{m} l_{j}, \sum_{j=1}^{m} m_{j}, \sum_{j=1}^{m} u_{j}\right) .
$$

The reciprocal value of the vector for (7) is further calculated with the following results:

$$
\left[\sum_{i=1}^{n} \sum_{j=1}^{m} \widetilde{M}_{g_{i}}^{j}\right]^{-1}=\left(\frac{1}{\sum_{j=1}^{m} u_{j}}, \frac{1}{\sum_{j=1}^{m} m_{j}}, \frac{1}{\sum_{j=1}^{m} l_{j}}\right) .
$$

Step 3.7. The degree of possibility of $\widetilde{M}_{2}=\left(l_{2}, m_{2}, u_{2}\right) \geq \widetilde{M}_{1}=$ $\left(l_{1}, m_{1}, u_{1}\right)$ is defined as follows:

$$
V\left(\widetilde{M}_{2} \geq \widetilde{M}_{1}\right)=\sup _{y \geq x}\left[\min \left(u_{\widetilde{M}_{1}}(x), u_{\widetilde{M}_{2}}(y)\right)\right] .
$$

Using the concept of triangular membership function, (9) can be rewritten as follows:

$$
\begin{array}{r}
V\left(\widetilde{M}_{2} \geq \widetilde{M}_{1}\right)=\operatorname{hgt}\left(\widetilde{M}_{1} \cap \widetilde{M}_{2}\right)=u_{\widetilde{M}_{1}}(d) \\
\quad= \begin{cases}1, & \text { if } m_{2} \geq m_{1} \\
\frac{l_{2}-u_{1}}{\left(m_{2}-u_{2}\right)-\left(m_{1}-l_{1}\right)}, & \text { if } l_{1}<u_{2} \\
0, & \text { otherwise, }\end{cases}
\end{array}
$$

where $d$ represents the abscissa value of the intersection of the two membership functions $u_{\widetilde{M}_{1}}$ and $u_{\widetilde{M}_{2}}$, and its corresponding ordinate value $D$ is $\left(\widetilde{M}_{2} \geq \widetilde{M}_{1}\right)$, meaning a degree whereby the fuzzy number $\widetilde{M}_{2}$ is higher than $\widetilde{M}_{1}$ (see Figure 2); thus $V\left(\widetilde{M}_{1} \geq \widetilde{M}_{2}\right)$ and $V\left(\widetilde{M}_{2} \geq \widetilde{M}_{1}\right)$ must be obtained to enable the comparison of the fuzzy numbers $\widetilde{M}_{1}$ and $\widetilde{M}_{2}$.

Step 3.8. Define $\widetilde{M}_{i}(i=1,2, \ldots, k)$ as the probability value of a particular convex fuzzy number that is larger than that of convex fuzzy number $k$ :

$$
\begin{aligned}
V & \left(\widetilde{M}>\widetilde{M}_{1}, \widetilde{M}_{2}, \ldots, \widetilde{M}_{k}\right)=V\left[\left(\widetilde{M}>\widetilde{M}_{1}\right)\right. \text { and } \\
& \left.\left(\widetilde{M}>\widetilde{M}_{2}\right) \text { and }, \ldots,\left(\widetilde{M}>\widetilde{M}_{k}\right)\right] \\
\quad & \min V\left[\left(\widetilde{M}>\widetilde{M}_{i}\right)\right] .
\end{aligned}
$$


TABLE 4: Unweighted supermatrix.

\begin{tabular}{lcccccccccccccccc}
\hline & \multirow{3}{*}{ Goal } & Stage & \multicolumn{1}{c}{ P2 } & P3 & C1a & C1b & C1c & C2a & C2b & C2c & C3a & C3b & C3c & A1 & A2 & A3 \\
\hline Goal & 0.000 & 0.000 & 0.000 & 0.000 & 0.000 & 0.000 & 0.000 & 0.000 & 0.000 & 0.000 & 0.000 & 0.000 & 0.000 & 1.000 & 1.000 & 1.000 \\
P1 & 0.607 & 0.580 & 0.430 & 0.463 & 0.000 & 0.000 & 0.000 & 0.000 & 0.000 & 0.000 & 0.000 & 0.000 & 0.000 & 0.000 & 0.000 & 0.000 \\
P2 & 0.338 & 0.097 & 0.206 & 0.086 & 0.000 & 0.000 & 0.000 & 0.000 & 0.000 & 0.000 & 0.000 & 0.000 & 0.000 & 0.000 & 0.000 & 0.000 \\
P3 & 0.056 & 0.323 & 0.364 & 0.4510 & 0.000 & 0.000 & 0.000 & 0.000 & 0.000 & 0.000 & 0.000 & 0.000 & 0.000 & 0.000 & 0.000 & 0.000 \\
\hline C1a & 0.000 & 0.277 & 0.000 & 0.000 & 0.469 & 0.288 & 0.440 & 0.000 & 0.000 & 0.000 & 0.000 & 0.000 & 0.000 & 0.000 & 0.000 & 0.000 \\
C1b & 0.000 & 0.265 & 0.000 & 0.000 & 0.220 & 0.222 & 0.084 & 0.000 & 0.000 & 0.000 & 0.000 & 0.000 & 0.000 & 0.000 & 0.000 & 0.000 \\
C1c & 0.000 & 0.459 & 0.000 & 0.000 & 0.311 & 0.490 & 0.476 & 0.000 & 0.000 & 0.000 & 0.000 & 0.000 & 0.000 & 0.000 & 0.000 & 0.000 \\
\hline C2a & 0.000 & 0.000 & 0.452 & 0.000 & 0.000 & 0.000 & 0.000 & 0.423 & 0.522 & 0.402 & 0.000 & 0.000 & 0.000 & 0.000 & 0.000 & 0.000 \\
C2b & 0.000 & 0.000 & 0.303 & 0.000 & 0.000 & 0.000 & 0.000 & 0.233 & 0.098 & 0.193 & 0.000 & 0.000 & 0.000 & 0.000 & 0.000 & 0.000 \\
C2c & 0.000 & 0.000 & 0.244 & 0.000 & 0.000 & 0.000 & 0.000 & 0.344 & 0.380 & 0.405 & 0.000 & 0.000 & 0.000 & 0.000 & 0.000 & 0.000 \\
\hline C3a & 0.000 & 0.000 & 0.000 & 0.268 & 0.000 & 0.000 & 0.000 & 0.000 & 0.000 & 0.000 & 0.413 & 0.481 & 0.279 & 0.000 & 0.000 & 0.000 \\
C3b & 0.000 & 0.000 & 0.000 & 0.219 & 0.000 & 0.000 & 0.000 & 0.000 & 0.000 & 0.000 & 0.295 & 0.272 & 0.229 & 0.000 & 0.000 & 0.000 \\
C3c & 0.000 & 0.000 & 0.000 & 0.513 & 0.000 & 0.000 & 0.000 & 0.000 & 0.000 & 0.000 & 0.292 & 0.247 & 0.492 & 0.000 & 0.000 & 0.000 \\
\hline A1 & 0.000 & 0.000 & 0.000 & 0.000 & 0.670 & 0.579 & 0.667 & 0.272 & 0.429 & 0.167 & 0.218 & 0.275 & 0.232 & 0.470 & 0.365 & 0.326 \\
A2 & 0.000 & 0.000 & 0.000 & 0.000 & 0.112 & 0.264 & 0.116 & 0.242 & 0.285 & 0.410 & 0.331 & 0.288 & 0.292 & 0.095 & 0.351 & 0.216 \\
A3 & 0.000 & 0.000 & 0.000 & 0.000 & 0.218 & 0.157 & 0.217 & 0.486 & 0.286 & 0.423 & 0.452 & 0.438 & 0.476 & 0.435 & 0.284 & 0.458 \\
\hline
\end{tabular}

Assume

$$
d\left(A_{i}\right)=\min V\left[\left(\widetilde{S}_{i}>\widetilde{S}_{k}\right)\right], \quad k=1,2, \ldots, n ; k \neq i .
$$

Thus, the weight vector is

$$
\begin{aligned}
W^{\prime}= & {\left[d^{\prime}\left(A_{1}\right), d^{\prime}\left(A_{2}\right), \ldots, d^{\prime}\left(A_{n}\right)\right]^{T}, } \\
& \text { where } A_{1}(i=1,2, \ldots, n) \text { represents } n \text { elements. }
\end{aligned}
$$

Step 3.9. The normalized weight vector is obtained using the normalization operation:

$$
\begin{array}{r}
W=\left[d\left(A_{1}\right), d\left(A_{2}\right), \ldots, d\left(A_{n}\right)\right]^{T}, \\
\text { where } W \text { is a nonfuzzy number. }
\end{array}
$$

Step 4. The preferences of experts and scholars are consolidated using the integrative method.

Step 5. The optimal method to facilitate snack food transaction efficiency can be determined by compiling the evaluation factor weights.

Step 6. The optimal channel plans for snack food dealers are selected.

\section{Empirical Case Analysis}

Using fresh snack foods as the research subject, this study surveyed four experts in snack food sales, marketing, and public relations and four scholars in marketing research. A supermatrix was constructed from the survey data according to the network framework in Figure 1, after which a supermatrix operation was conducted using Super Decisions software. To meet the column-stochastic principle, the unweighted supermatrix (see Table 4) was subjected to weighting, whereby the preliminary matrix for the weighted supermatrix was obtained (see Table 5). The weighted supermatrix was minimized to obtain the relative weights for each criterion, meaning that the weighted supermatrix was multiplied by $2 k+1$ power, after which the dependencies gradually converged to yield a limiting supermatrix (see Table 6).

The analysis results revealed that in terms of the influence on customers' decision-making in fresh snack food purchases, the transaction costs were in the order of prepurchase, purchase, and postpurchase transaction costs (weights = $0.564>0.229>0.207)$. In terms of each dimension of decision-making, under prepurchase transaction costs, the provision of food safety assurance had the maximal impact (weight $=0.440$ ), followed by providing sufficient information and then food testing. At the purchase stage, protecting personal information leakage had the most notable impact (weight $=0.447)$, followed by multiple payment methods and waiting time. Finally, at the postpurchase stage, the waiting time for product delivery had the strongest influence (weight $=0.441$ ), followed by order tracking transparency and delivery progress notification; the various decision-making dimensions and their transaction cost factor weights are shown in Table 7. From Table 8, in terms of the ideal sales channels for snack food dealers, retail stores were found to be the optimal mode, followed by home delivery and cash on delivery (weights $=0.438>0.360>0.202$ ).

\section{Conclusions}

Prepurchase transaction costs have the greatest effect on customers' purchasing of fresh snack foods, with "providing food safety assurance," "sufficient information exposure," and "food testing" identified as the top three criteria in the 
TABLE 5: Weighted supermatrix.

\begin{tabular}{|c|c|c|c|c|c|c|c|c|c|c|c|c|c|c|c|c|}
\hline & \multirow{2}{*}{ Goal } & \multicolumn{3}{|c|}{ Stage } & \multicolumn{9}{|c|}{ Criteria } & \multicolumn{3}{|c|}{ Alternatives } \\
\hline & & P1 & $\mathrm{P} 2$ & P3 & Cla & $\mathrm{Clb}$ & $\mathrm{Clc}$ & $\mathrm{C} 2 \mathrm{a}$ & $\mathrm{C} 2 \mathrm{~b}$ & $\mathrm{C} 2 \mathrm{c}$ & $\mathrm{C} 3 \mathrm{a}$ & $\mathrm{C} 3 \mathrm{~b}$ & $\mathrm{C} 3 \mathrm{c}$ & $\mathrm{A} 1$ & A2 & A3 \\
\hline Goal & 0.000 & 0.000 & 0.000 & 0.000 & 0.000 & 0.000 & 0.000 & 0.000 & 0.000 & 0.000 & 0.000 & 0.000 & 0.000 & 0.500 & 0.500 & 0.500 \\
\hline P1 & 0.607 & 0.290 & 0.215 & 0.232 & 0.000 & 0.000 & 0.000 & 0.000 & 0.000 & 0.000 & 0.000 & 0.000 & 0.000 & 0.000 & 0.000 & 0.000 \\
\hline $\mathrm{P} 2$ & 0.338 & 0.048 & 0.103 & 0.043 & 0.000 & 0.000 & 0.000 & 0.000 & 0.000 & 0.000 & 0.000 & 0.000 & 0.000 & 0.000 & 0.000 & 0.000 \\
\hline P3 & 0.056 & 0.162 & 0.182 & 0.226 & 0.000 & 0.000 & 0.000 & 0.000 & 0.000 & 0.000 & 0.000 & 0.000 & 0.000 & 0.000 & 0.000 & 0.000 \\
\hline Cla & 0.000 & 0.138 & 0.000 & 0.000 & 0.235 & 0.144 & 0.220 & 0.000 & 0.000 & 0.000 & 0.000 & 0.000 & 0.000 & 0.000 & 0.000 & 0.000 \\
\hline $\mathrm{Clb}$ & 0.000 & 0.132 & 0.000 & 0.000 & 0.110 & 0.111 & 0.042 & 0.000 & 0.000 & 0.000 & 0.000 & 0.000 & 0.000 & 0.000 & 0.000 & 0.000 \\
\hline $\mathrm{Clc}$ & 0.000 & 0.229 & 0.000 & 0.000 & 0.155 & 0.245 & 0.238 & 0.000 & 0.000 & 0.000 & 0.000 & 0.000 & 0.000 & 0.000 & 0.000 & 0.000 \\
\hline $\mathrm{C} 2 \mathrm{a}$ & 0.000 & 0.000 & 0.226 & 0.000 & 0.000 & 0.000 & 0.000 & 0.211 & 0.261 & 0.201 & 0.000 & 0.000 & 0.000 & 0.000 & 0.000 & 0.000 \\
\hline $\mathrm{C} 2 \mathrm{~b}$ & 0.000 & 0.000 & 0.152 & 0.000 & 0.000 & 0.000 & 0.000 & 0.117 & 0.049 & 0.096 & 0.000 & 0.000 & 0.000 & 0.000 & 0.000 & 0.000 \\
\hline $\mathrm{C} 2 \mathrm{c}$ & 0.000 & 0.000 & 0.122 & 0.000 & 0.000 & 0.000 & 0.000 & 0.172 & 0.190 & 0.203 & 0.000 & 0.000 & 0.000 & 0.000 & 0.000 & 0.000 \\
\hline $\mathrm{C} 3 \mathrm{a}$ & 0.000 & 0.000 & 0.000 & 0.134 & 0.000 & 0.000 & 0.000 & 0.000 & 0.000 & 0.000 & 0.207 & 0.241 & 0.140 & 0.000 & 0.000 & 0.000 \\
\hline $\mathrm{C} 3 \mathrm{~b}$ & 0.000 & 0.000 & 0.000 & 0.110 & 0.000 & 0.000 & 0.000 & 0.000 & 0.000 & 0.000 & 0.148 & 0.136 & 0.115 & 0.000 & 0.000 & 0.000 \\
\hline $\mathrm{C} 3 \mathrm{c}$ & 0.000 & 0.000 & 0.000 & 0.257 & 0.000 & 0.000 & 0.000 & 0.000 & 0.000 & 0.000 & 0.146 & 0.123 & 0.246 & 0.000 & 0.000 & 0.000 \\
\hline $\mathrm{A} 1$ & 0.000 & 0.000 & 0.000 & 0.000 & 0.335 & 0.289 & 0.334 & 0.136 & 0.215 & 0.083 & 0.109 & 0.137 & 0.116 & 0.235 & 0.182 & 0.163 \\
\hline A2 & 0.000 & 0.000 & 0.000 & 0.000 & 0.056 & 0.132 & 0.058 & 0.121 & 0.143 & 0.205 & 0.165 & 0.144 & 0.146 & 0.047 & 0.176 & 0.108 \\
\hline A3 & 0.000 & 0.000 & 0.000 & 0.000 & 0.109 & 0.078 & 0.109 & 0.243 & 0.143 & 0.212 & 0.226 & 0.219 & 0.238 & 0.218 & 0.142 & 0.229 \\
\hline
\end{tabular}

TABLE 6: Limiting supermatrix.

\begin{tabular}{|c|c|c|c|c|c|c|c|c|c|c|c|c|c|c|c|c|}
\hline & \multirow{2}{*}{ Goal } & \multicolumn{3}{|c|}{ Stage } & \multicolumn{9}{|c|}{ Criteria } & \multicolumn{3}{|c|}{ Alternatives } \\
\hline & & $\mathrm{P} 1$ & P2 & P3 & Cla & $\mathrm{Clb}$ & $\mathrm{Clc}$ & $\mathrm{C} 2 \mathrm{a}$ & $\mathrm{C} 2 \mathrm{~b}$ & $\mathrm{C} 2 \mathrm{c}$ & $\mathrm{C} 3 \mathrm{a}$ & $\mathrm{C} 3 \mathrm{~b}$ & $\mathrm{C} 3 \mathrm{c}$ & $\mathrm{A} 1$ & A2 & A3 \\
\hline Goal & 0.143 & 0.143 & 0.143 & 0.143 & 0.143 & 0.143 & 0.143 & 0.143 & 0.143 & 0.143 & 0.143 & 0.143 & 0.143 & 0.143 & 0.143 & 0.143 \\
\hline P1 & 0.161 & 0.161 & 0.161 & 0.161 & 0.161 & 0.161 & 0.161 & 0.161 & 0.161 & 0.161 & 0.161 & 0.161 & 0.161 & 0.161 & 0.161 & 0.161 \\
\hline $\mathrm{P} 2$ & 0.065 & 0.065 & 0.065 & 0.065 & 0.065 & 0.065 & 0.065 & 0.065 & 0.065 & 0.065 & 0.065 & 0.065 & 0.065 & 0.065 & 0.065 & 0.065 \\
\hline P3 & 0.059 & 0.059 & 0.059 & 0.059 & 0.059 & 0.059 & 0.059 & 0.059 & 0.059 & 0.059 & 0.059 & 0.059 & 0.059 & 0.059 & 0.059 & 0.059 \\
\hline $\mathrm{Cla}$ & 0.056 & 0.056 & 0.056 & 0.056 & 0.056 & 0.056 & 0.056 & 0.056 & 0.056 & 0.056 & 0.056 & 0.056 & 0.056 & 0.056 & 0.056 & 0.056 \\
\hline $\mathrm{Clb}$ & 0.034 & 0.034 & 0.034 & 0.034 & 0.034 & 0.034 & 0.034 & 0.034 & 0.034 & 0.034 & 0.034 & 0.034 & 0.034 & 0.034 & 0.034 & 0.034 \\
\hline $\mathrm{Clc}$ & 0.071 & 0.071 & 0.071 & 0.071 & 0.071 & 0.071 & 0.071 & 0.071 & 0.071 & 0.071 & 0.071 & 0.071 & 0.071 & 0.071 & 0.071 & 0.071 \\
\hline $\mathrm{C} 2 \mathrm{a}$ & 0.029 & 0.029 & 0.029 & 0.029 & & 0.029 & & 0.029 & 0.029 & 0.029 & 0.029 & 0.029 & 0.029 & 0.029 & 0.029 & 0.029 \\
\hline $\mathrm{C} 2 \mathrm{~b}$ & 0.016 & 0.016 & 0.016 & 0.016 & 0.016 & 0.016 & 0.016 & 0.016 & 0.016 & 0.016 & 0.016 & 0.016 & 0.016 & 0.016 & 0.016 & 0.016 \\
\hline $\mathrm{C} 2 \mathrm{c}$ & 0.020 & 0.020 & 0.020 & 0.020 & 0.020 & 0.020 & 0.020 & 0.020 & 0.020 & 0.020 & 0.020 & 0.020 & 0.020 & 0.020 & 0.020 & 0.020 \\
\hline $\mathrm{C} 3 \mathrm{a}$ & 0.019 & 0.019 & 0.019 & 0.019 & 0.019 & 0.019 & 0.019 & 0.019 & 0.019 & 0.019 & 0.019 & 0.019 & 0.019 & 0.019 & 0.019 & 0.019 \\
\hline $\mathrm{C} 3 \mathrm{~b}$ & 0.014 & 0.014 & 0.014 & 0.014 & 0.014 & 0.014 & 0.014 & 0.014 & 0.014 & 0.014 & 0.014 & 0.014 & 0.014 & 0.014 & 0.014 & 0.014 \\
\hline $\mathrm{C} 3 \mathrm{c}$ & 0.026 & 0.026 & 0.026 & 0.026 & 0.026 & 0.026 & 0.026 & 0.026 & 0.026 & 0.026 & 0.026 & 0.026 & 0.026 & 0.026 & 0.026 & 0.026 \\
\hline $\mathrm{A} 1$ & 0.125 & 0.125 & 0.125 & 0.125 & 0.125 & 0.125 & 0.125 & 0.125 & 0.125 & 0.125 & 0.125 & 0.125 & 0.125 & 0.125 & 0.125 & 0.125 \\
\hline A 2 & 0.058 & 0.058 & 0.058 & 0.058 & 0.058 & 0.058 & 0.058 & 0.058 & 0.058 & 0.058 & 0.058 & 0.058 & 0.058 & 0.058 & 0.058 & 0.058 \\
\hline A3 & 0.103 & 0.103 & 0.103 & 0.103 & 0.103 & 0.103 & 0.103 & 0.103 & 0.103 & 0.103 & 0.103 & 0.103 & 0.103 & 0.103 & 0.103 & 0.103 \\
\hline
\end{tabular}

overall factor ranking. Food distributors are also committed to providing food safety information and assurance on the food packaging (e.g., international Safe Quality Food and the Certified Agricultural Standards in Taiwan). Food safety incidents in 2008 (infant formula contaminated with melamine in China), 2011 (a plasticizer used as a replacement for palm oil in Taiwan), and 2013 (a series of food scandals in Taiwan) have had a marked effect on the sales, operations, and brand reputations of product manufacturers, dealers, and street vendors in Taiwan and even led to bankruptcy and problems with subsequent compensation. The food industries have adopted various approaches such as issuing press releases, holding press conferences, and even providing raw material source verifications, product assurance, and food production records at retail stores to restore customer trust. The incidents highlight the practical importance of prepurchase transaction cost factors. The results of this study can also be verified by manufacturers' responses to food safety scandals and their practical operations.

The protection of personal information has the largest effect on customers' purchasing decisions. In practical terms, leakage of such information can be roughly divided into loss of personal information and theft of financial information. To demonstrate efforts aimed at protecting personal information, industries can reinforce customer confidence by providing written guarantees or online confidentiality 
TABLE 7: Decision-making dimension and transaction cost factors weights.

\begin{tabular}{|c|c|c|c|c|c|c|c|c|}
\hline Dimension & Weights & Ranking & & Criteria & $\begin{array}{c}\text { Weights } \\
\text { (local) }\end{array}$ & $\begin{array}{l}\text { Weights } \\
\text { (global) }\end{array}$ & $\begin{array}{c}\text { Ranking } \\
\text { (local) }\end{array}$ & $\begin{array}{l}\text { Ranking } \\
\text { (global) }\end{array}$ \\
\hline \multirow{3}{*}{ Prepurchasing } & \multirow{3}{*}{0.564} & \multirow{3}{*}{1} & Cla & Sufficient information exposure & 0.347 & 0.196 & 2 & 2 \\
\hline & & & $\mathrm{Clb}$ & Food testing & 0.213 & 0.120 & 3 & 3 \\
\hline & & & $\mathrm{Clc}$ & Food safety assurance provided & 0.440 & 0.248 & 1 & 1 \\
\hline \multirow{3}{*}{ Purchasing } & \multirow{3}{*}{0.229} & \multirow{3}{*}{3} & $\mathrm{C} 2 \mathrm{a}$ & Personal information leak prevention & 0.447 & 0.102 & 1 & 4 \\
\hline & & & $\mathrm{C} 2 \mathrm{~b}$ & Waiting time & 0.246 & 0.056 & 3 & 8 \\
\hline & & & $\mathrm{C} 2 \mathrm{c}$ & Multiple payment methods & 0.308 & 0.071 & 2 & 6 \\
\hline \multirow{3}{*}{ Postpurchasing } & \multirow{3}{*}{0.207} & \multirow{3}{*}{2} & C3a & Order tracking transparency & 0.319 & 0.066 & 2 & 7 \\
\hline & & & $\mathrm{C} 3 \mathrm{~b}$ & Delivery progress notification & 0.240 & 0.050 & 3 & 9 \\
\hline & & & $\mathrm{C} 3 \mathrm{c}$ & Waiting time for product delivery & 0.441 & 0.091 & 1 & 5 \\
\hline
\end{tabular}

TABLE 8: Weights of sales channels.

\begin{tabular}{lccc}
\hline Alternatives & Retail store & Home delivery & Cash on delivery \\
\hline Weights & 0.438 & 0.360 & 0.202 \\
\hline
\end{tabular}

contracts (e.g., mobile payment). Regarding the theft of financial information, assurance can be given by displaying the electronic security mechanism being used to ensure system security and privacy (e.g., secure sockets layer encryption). Customers who are concerned about personal computer system vulnerabilities and online transaction systems naturally prefer to visit stores to purchase items in person. Despite the relative weight of postpurchase transaction costs being the lowest, the waiting time for product delivery was ranked fifth among all transaction cost factors, indicating the high value placed by food manufactures on the level of freshness when products reach their customers. Through the approaches of order notification or instant inquiry, customers can track the product delivery progress and determine whether the products are affected by adverse environmental conditions (e.g., too much time in transit) during the delivery process, which results in unsatisfactory quality. Concurrently, numerous food distributors have also attempted to incorporate multichannel cooperation into their practical operations and have maintained satisfactory food freshness with their deliveries.

The optimal sales channel for snack food dealers is retail stores. Channel decision-makers can not only display products and their complete information but also provide demonstrations and food testing. In particular, customers who are unfamiliar with a product require more information for searching and inquiring about the costs, and dealers can reduce customers' prepurchase costs the most by selling through retail store channels. Many examples of the research findings are evident in food business practices. Some food distributors or microenterprises initially sold their products online, after which they opened physical locations and developed into chain stores. Businesses that were initially brick-and-mortar stores can utilize their stores to develop online sales, thereby achieving home delivery or channels for picking up merchandizes at the specified point.
In this study, the influences of the various transaction cost factors on customers' purchasing behaviors at different stages of purchasing were modeled for discussion. The findings may provide a reference for product suppliers or microenterprise channel development, which can be expanded to marketing and inventory management applications in food industries. In terms of developing the research methods, future studies can compare the ranking of different transaction cost factors or channel assessments under different MCDM approaches, the results of which can be verified through interviews with enterprises or experts.

\section{Conflicts of Interest}

The author declares that there are no financial or other conflicts of interest.

\section{References}

[1] J. F. Engel, D. T. Kollat, and R. D. Blackwell, Consumer Behavior, Dryden Press, Fort Worth, Tex, USA, 7th edition, 1993.

[2] R. D. Blackwell, P. W. Miniard, and J. F. Engle, Consumer Behavior, Harcount, Inc., Orland, Calif, USA, 9th edition, 2001.

[3] J. P. Peter and J. Olson, Consumer Behaviour and Marketing Strategy, McGraw-Hill, 7th edition, 2005.

[4] O. E. Williamson, "Transaction cost economics: the natural progression," Journal of Retailing, vol. 86, no. 3, pp. 215-226, 2010.

[5] R. Coase, "Price theory," in The Nature of the Firm, vol. 36, pp. 331-351, Irwin, 1952.

[6] T. S. H. Teo and Y. Yu, "Online buying behavior: a transaction cost economics perspective," Omega, vol. 33, no. 5, pp. 451-465, 2005.

[7] O. E. Williamson, Market and Hierarchies: Analysis and Antitrust Implications, Free Press, New York, NY, USA, 1975.

[8] T.-P. Liang and J.-S. Huang, "An empirical study on consumer acceptance of products in electronic markets: a transaction cost model," Decision Support Systems, vol. 24, no. 1, pp. 29-43, 1998.

[9] A. M. Degeratu, A. Rangaswamy, and J. Wu, "Consumer choice behavior in online and traditional supermarkets: the effects of brand name, price, and other search attributes," International Journal of Research in Marketing, vol. 17, no. 1, pp. 55-78, 2000. 
[10] I. Geyskens, K. Gielens, and M. G. Dekimpe, "The market valuation of Internet channel additions," Journal of Marketing, vol. 66, no. 2, pp. 102-119, 2002.

[11] P. C. Verhoef, S. A. Neslin, and B. Vroomen, "Multichannel customer management: understanding the research-shopper phenomenon," International Journal of Research in Marketing, vol. 24, no. 2, pp. 129-148, 2007.

[12] R. L. Benedicktus, M. K. Brady, P. R. Darke, and C. M. Voorhees, "Conveying trustworthiness to online consumers: reactions to consensus, physical store presence, brand familiarity, and generalized suspicion," Journal of Retailing, vol. 86, no. 4, pp. 310-323, 2010.

[13] K. H. Hahn and J. Kim, "The effect of offline brand trust and perceived internet confidence on online shopping intention in the integrated multi-channel context," International Journal of Retail and Distribution Management, vol. 37, no. 2, pp. 126-141, 2009.

[14] K. Kooli, K. B. Mansour, and R. Utama, "Determinants of online trust and their impact on online purchase intention," International Journal of Technology Marketing, vol. 9, no. 3, pp. 305-319, 2014.

[15] R. M. Grüschow, J. Kemper, and M. Brettel, "How do different payment methods deliver cost and credit efficiency in electronic commerce?" Electronic Commerce Research and Applications, vol. 18, pp. 27-36, 2016.

[16] L. Zhang and L. B. Oh, "Determinants of multichannel consumer switching behavior: a comparative analysis of search and experience products," in WHICEB, pp. 205-212, Wuhan, China, 2013.

[17] J. E. Workman and S. Cho, "Gender, fashion consumer group, need for touch and Korean apparel consumers' shopping channel preference," International Journal of Consumer Studies, vol. 37, no. 5, pp. 522-529, 2013.

[18] K.-P. Chiang and R. R. Dholakia, "Factors driving consumer intention to shop online: an empirical investigation," Journal of Consumer Psychology, vol. 13, no. 1-2, pp. 177-183, 2003.

[19] M.-S. Chen, H.-J. Chang, C.-W. Huang, and C.-N. Liao, "Channel coordination and transaction cost: a game-theoretic analysis," Industrial Marketing Management, vol. 35, no. 2, pp. 178190, 2006.

[20] U. Konuş, S. A. Neslin, and P. C. Verhoef, “The effect of search channel elimination on purchase incidence, order size and channel choice," International Journal of Research in Marketing, vol. 31, no. 1, pp. 49-64, 2014.

[21] S.-Y. Chou, G. C. Shen, H.-C. Chiu, and Y.-T. Chou, "Multichannel service providers' strategy: understanding customers' switching and free-riding behavior," Journal of Business Research, vol. 69, no. 6, pp. 2226-2232, 2016.

[22] H. Hu and C. R. Jasper, "The impact of consumer shopping experience on consumer channel decision," Academy of Marketing Studies Journal, vol. 19, no. 1, pp. 213-224, 2015.

[23] M. Stone, M. Hobbs, and M. Khaleeli, "Multichannel customer management: the benefits and challenges," Journal of Database Marketing, vol. 10, no. 1, pp. 39-52, 2002.

[24] Y.-H. Joo and M. H.-J. Park, "Information search and purchase channel choice across in-home shopping retail formats," Academy of Marketing Studies Journal, vol. 12, no. 2, pp. 49-61, 2008.

[25] R. K. Tyagi, “Technological advances, transaction costs, and consumer welfare," Marketing Science, vol. 23, no. 3, pp. 335466, 2004.
[26] P.-Y. Chen, M.-S. Chen, and C.-Y. Lin, "The inventory model of the effect of product validity on consumer purchase intension," ICIC Express Letters, vol. 7, no. 7, pp. 2115-2120, 2013.

[27] P.-Y. Chen, "The effect of adopting new storage methods for extending product validity periods on manufacturers expected inventory costs," Scientific World Journal, vol. 2014, Article ID 813982, 2014.

[28] M. Nicholson, I. Clarke, and M. Blakemore, "One brand, three ways to shop: situational variables and multichannel consumer behaviour," The International Review of Retail, Distribution and Consumer Research, vol. 12, no. 2, pp. 131-148, 2002.

[29] D. D. Schoenbachler and G. L. Gordon, "Multi-channel shopping: understanding what drives channel choice," Journal of Consumer Marketing, vol. 19, no. 1, pp. 42-53, 2002.

[30] I.-H. Hann and C. Terwiesch, "Measuring the frictional costs of online transactions: the case of a name-your-own-price channel," Management Science, vol. 49, no. 11, pp. 1563-1579, 2003.

[31] R. Venkatesan, V. Kumar, and N. Ravishanker, "Multichannel shopping: causes and consequences," Journal of Marketing, vol. 71, no. 2, pp. 114-132, 2007.

[32] H.-j. Chang and P.-y. Chen, "An optimal demand function constructed by consumer willing-to-pay price and transaction cost," International Journal of Information and Management Sciences, vol. 19, no. 4, pp. 717-728, 2008.

[33] X. Pu, L. Gong, and X. Han, "Consumer free riding: coordinating sales effort in a dual-channel supply chain," Electronic Commerce Research and Applications, vol. 22, pp. 1-12, 2017.

[34] K. D. Chen and W. H. Hausman, "Mathematical properties of the optimal product line selection problem using choice-based conjoint analysis," Management Science, vol. 46, no. 2, pp. 327332, 2000.

[35] G. J. Klir, Z. Wang, and D. Harmanec, "Constructing fuzzy measures in expert systems," Fuzzy Sets and Systems, vol. 92, no. 2, pp. 251-264, 1997.

[36] H. J. Zimmermann, Fuzzy Set Theory-and Its Applications, Kluwer Academic, 2001.

[37] T. L. Saaty, The Analytic Network Process-Decision Making with Dependence and Feedback, RWS Publications, Pittsburgh, Pa, USA, 1996.

[38] T. L. Saaty and L. Vargas, Fundamentals of Decision-Making and Priority Theory: With the Analytic Hierarchy Process, RWS Publications, Pittsburgh, Pa, USA, 2000.

[39] L. A. Zadeh, "Fuzzy sets," Information and Control, vol. 8, no. 3, pp. 338-353, 1965.

[40] J. Razmi, M. S. Sangari, and R. Ghodsi, "Developing a practical framework for ERP readiness assessment using fuzzy analytic network process," Advances in Engineering Software, vol. 40, no. 11, pp. 1168-1178, 2009.

[41] S. Onut, S. S. Kara, and S. Mert, "Selecting the suitable material handling equipment in the presence of vagueness," International Journal of Advanced Manufacturing Technology, vol. 44, no. 7-8, pp. 818-828, 2009.

[42] S. Boran and K. Goztepe, "Development of a fuzzy decision support system for commodity acquisition using fuzzy analytic network process," Expert Systems with Applications, vol. 37, no. 3, pp. 1939-1945, 2010.

[43] S. Vinodh, R. Anesh Ramiya, and S. G. Gautham, "Application of fuzzy analytic network process for supplier selection in a manufacturing organisation," Expert Systems with Applications, vol. 38, no. 1, pp. 272-280, 2011. 
[44] G. Büyüközkan and G. Çifçi, "A novel hybrid MCDM approach based on fuzzy DEMATEL, fuzzy ANP and fuzzy TOPSIS to evaluate green suppliers," Expert Systems with Applications, vol. 39, no. 3, pp. 3000-3011, 2012.

[45] U. R. Tuzkaya and S. Önüt, "A fuzzy analytic network process based approach to transportation-mode selection between Turkey and Germany: a case study," Information Sciences, vol. 178, no. 15, pp. 3133-3146, 2008.

[46] Z. Ayağ and R. G. Özdemir, "An intelligent approach to machine tool selection through fuzzy analytic network process," Journal of Intelligent Manufacturing, vol. 22, no. 2, pp. 163-177, 2011.

[47] G. Büyüközkan and S. Güleryüz, "An integrated DEMATELANP approach for renewable energy resources selection in Turkey," International Journal of Production Economics, vol. 182, pp. 435-448, 2016.

[48] M. Nilashi, H. Ahmadi, A. Ahani, R. Ravangard, and O. B. Ibrahim, "Determining the importance of hospital information system adoption factors using fuzzy analytic network process (ANP)," Technological Forecasting \& Social Change, vol. 111, pp. 244-264, 2016.

[49] H. Tutunchi, A. Ostadrahimi, S. Mahboob, and S. J. Tabrizi, "Analysis of food insecurity and surveillance based on the fanp method in the northwest of Iran," Journal of Applied Sciences and Environmental Management, vol. 15, no. 4, pp. 617-624, 2011.

[50] A. Kamalian, "Identify and ranking key indicators performance of green supply chain using combinational method dematel and anp with fuzzy approach (the case food industry in iran)," International Journal of Business and Development Studies, vol. 5, no. 1, pp. 116-136, 2013.

[51] K. L. Chang, "Combined MCDM approaches for century-old Taiwanese food firm new product development project selection," British Food Journal, vol. 115, no. 8, pp. 1197-1210, 2013.

[52] D. Kurniawati and H. Yuliando, "Productivity improvement of small scale medium enterprises (SMEs) on food products: case at Yogyakarta province, Indonesia," Agriculture and Agricultural Science Procedia, vol. 3, pp. 189-194, 2015.

[53] C. Khan, S. Anwar, S. Bashir, A. Rauf, and A. Amin, "Site selection for food distribution using rough set approach and TOPSIS method," Journal of Intelligent and Fuzzy Systems, vol. 29, no. 6, pp. 2413-2419, 2015.

[54] A. Baviera-Puig, T. Gómez-Navarro, M. García-Melón, and G. García-Martínez, "Assessing the communication quality of CSR reports. A case study on four spanish food companies," Sustainability, vol. 7, no. 8, pp. 11010-11031, 2015.

[55] A. R. Linnemann, E. M. Hendrix, R. Apaiah, and T. A. van Boekel, "Food chain design using multi criteria decision making, an approach to complex design issues," NJAS - Wageningen Journal of Life Sciences, vol. 72-73, pp. 13-21, 2015.

[56] K. Govindan, M. Kadziński, and R. Sivakumar, "Application of a novel promethee-based method for construction of a group compromise ranking to prioritization of green suppliers in food supply chain," Omega, 2016, (In press).

[57] A. S. Slamet, A. Nakayasu, R. Astuti, and N. M. Rachman, "Risk assessment of papaya supply chain: an Indonesian case study," International Business Management, vol. 11, no. 2, pp. 508-521, 2017.

[58] G. J. Lai, “The feasibility of scale-reduction of the analytic hierarchy process," Journal of Education and Psychology, vol. 21, no. 1, pp. 17-35, 1998.

[59] D. Chang, "Applications of the extent analysis method on fuzzy AHP," European Journal of Operational Research, vol. 95, no. 3, pp. 649-655, 1996. 

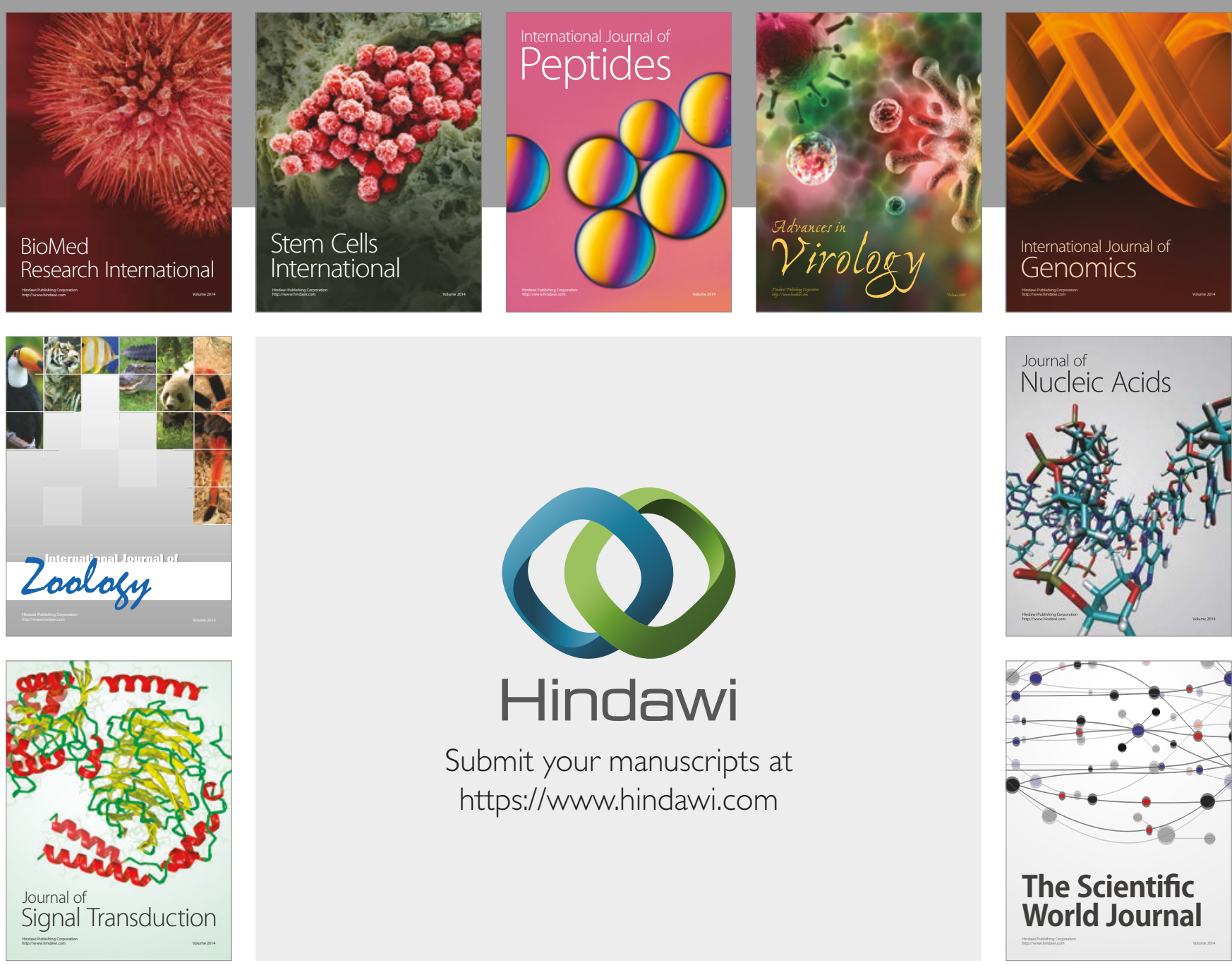

Submit your manuscripts at

https://www.hindawi.com
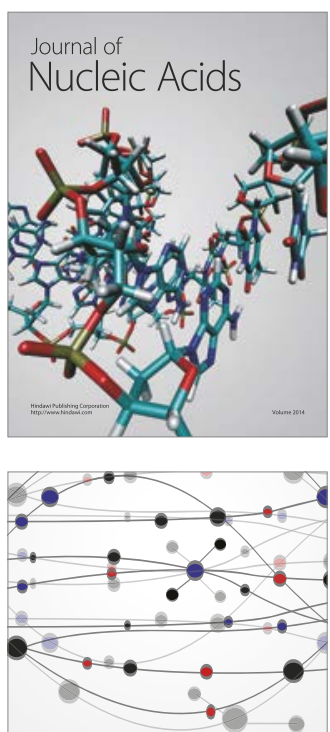

The Scientific World Journal

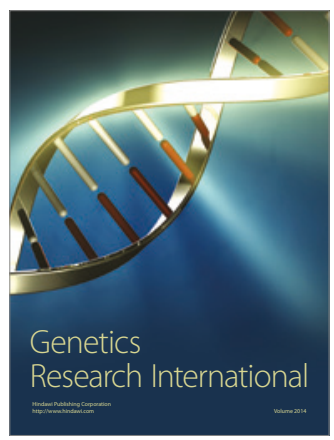

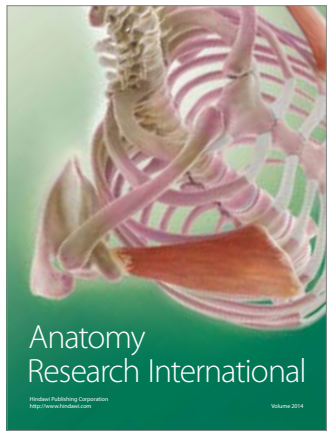

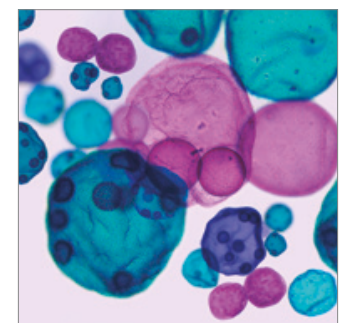

International Journal of Microbiology
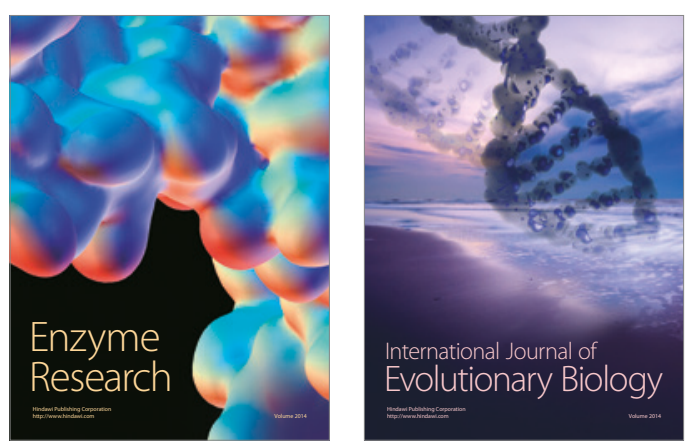
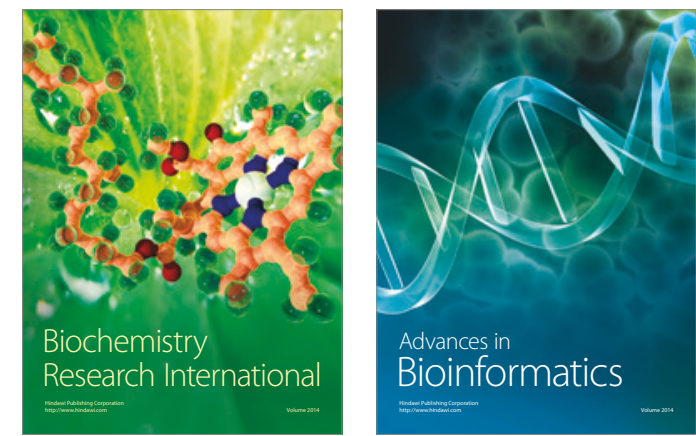

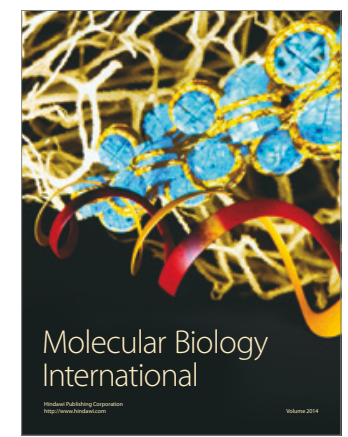

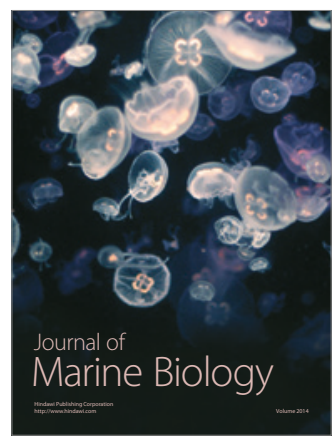

